\title{
Shiftwork and Alcohol Consumption: A Systematic Review of the Literature
}

\author{
Kneginja Richter ${ }^{a}$ Lukas Peter $^{\mathrm{a}}$ Andrea Rodenbeck ${ }^{c}$ Hans Günter Weess ${ }^{d}$ \\ Steffi G. Riedel-Heller ${ }^{b}$ Thomas Hillemacher ${ }^{a}$ \\ aUniversity Clinic for Psychiatry and Psychotherapy, Paracelsus Medical University Nuremberg, Nuremberg, \\ Germany; b Arbeitsmedizin und Public Health (ISAP), Institut für Sozialmedizin, Medizinische Fakultät, \\ Universität Leipzig, Leipzig, Germany; ' Evangelisches Fachkrankenhaus Göttingen-Weende, Göttingen, Germany; \\ dPfalzklinikum Interdisziplinäres Schlafzentrum, Klingenmünster, Germany
}

\section{Keywords}

Sleep · Shiftwork · Work schedule · Alcohol · Binge drinking · Substance abuse $\cdot$ Chronobiology

\begin{abstract}
Introduction: Shiftwork can be a risk factor for a number of different somatic and psychological health conditions, especially sleep disorders. Shiftworkers sleep less than dayworkers, and $20-40 \%$ of them suffer from difficulties initiating and maintaining sleep, which result in reduced capacity for work and social life. A common coping strategy might be the use of alcohol, which presents a health and safety hazard as it further impairs sleep quality and exacerbates sleepiness in the workplace. This review aimed to assess the extent of such possible connections. Methods: We performed a systematic search of the scientific literature on shiftwork and alcohol consumption in PubMed, Psyclnfo, and Cochrane Library. Only original studies comparing shiftworkers with non-shiftworkers were included. The recommendations of the Preferred Reporting Items of Systematic Reviews and Meta-Analyses were followed. Results: Fourteen articles are included in this review. Six studies report some kind of connection between shift- or nightwork and alcohol consumption, espe-
\end{abstract}

cially as a sleep aid. Conflicting or negative results are reported by 3 studies. Discussion: Shiftwork, especially working at night and in rotation shifts, is associated with binge drinking disorder in different professions. The reasons for pathological consumption of alcohol can be self-medication of sleep problems or coping with stress and psychosocial problems typical for shiftwork. Nurses aged over 50 years represent one important risk group. These results can be important for preventive programs against sleep disorders, including measures other than drinking alcohol as a sleep aid in the workplace of shiftworkers.

(c) 2020 S. Karger AG, Basel

\section{Introduction}

An estimated $15-30 \%$ of the workforce in Western countries work in shifts [1-3]. In many cases, shiftwork includes work at night [4]. Working in rotating shifts with work at night can be a risk factor for different health conditions such as cardiological [5], metabolical [6,7], or oncological [8-11] diseases; depression [12]; fatigue at work; tiredness; and sleep disturbances [1, 13-15]. Approximately $10 \%$ of shiftworkers fulfill the criteria for the diag-

$\begin{aligned} & \text { karger@karger.com } \\ & \text { www.karger.com/ear }\end{aligned}$
Karger ${ }^{\prime /}$

Prof. Kneginja Richter 
nosis of shiftwork sleep disorder (SWSD) and an additional $25-30 \%$ experience symptoms of insomnia or excessive sleepiness $[1,2]$.

A number of pathophysiological pathways play a role in the etiology of somatic and psychological disturbances associated with shiftwork: reduced production of melatonin at night, irregular secretion of cortisol, disturbed sleep-wake cycles, social jet-lag, shortened sleep, and unhealthy lifestyle habits $[10,12,16-21]$. The psychosocial stress associated with shiftwork and different strategies used to cope with it have been examined repeatedly over the last decades [22-24]. One possible coping strategy, especially for the sleep problems often associated with shiftwork $[1,13]$, is the use of alcohol $[25,26]$. It has been suggested that shiftworkers may consume more alcohol than dayworkers as a sleep aid to compensate for sleep difficulties associated with work schedules, ultimately resulting in greater consumption. A large study in Australian workers suggested that those on nonstandard schedules (outside 8 a.m. -6 p.m., Monday-Friday) do not drink more but are at increased odds of binge drinking (heavy periods of drinking followed by abstinence) than workers on standard schedules [27, 28].

This is especially problematic as alcohol use seems to impair sleep quality and increase sleepiness even further $[29,30]$. The result might be increased alcohol consumption and binge drinking, defined here as 5 or more drinks in a row for men and 4 or more drinks in a row for women [31]. Levels and patterns of alcohol consumption might differ between day- and shiftworkers and between male and female shiftworkers.

One study indicates that alcohol consumption may be influenced by occupational factors and is strongly correlated with specific worksite and time of shift [32]. Working in shifts in the processing/manufacturing, transport, artistic/literary/recreational, and sales area sectors has been associated with major alcohol-related problems [33].

Studies have shown that adverse health consequences, motor vehicle accidents, increased alcohol and medication use, and serious medical errors can occur as a result of both sleep deprivation and shiftwork [34]. Relative to individuals working during the day, those on shiftwork, particularly rotating and night shifts, showed greater adverse effects. These included poorer sleep, altered eating habits, greater alcohol consumption, greater incidence of sickness absence, and greater incidence of work-related injuries $[35,36]$. Regarding the risk for accidents as well as the working capacity, high alcohol intake during working hours has to be criticized [37].

\section{Methods}

A systematic review was performed on studies about alcohol intake by shiftworkers as compared with workers not on a shift roster. Only original studies with quantitative results specifically comparing shift- or nightworkers with non-shiftworkers regarding levels or patterns of alcohol consumption were selected. The review was limited to publications written in English or German. The recommendations of the Preferred Reporting Items of Systematic Reviews and Meta-Analyses[38] were followed where applicable.

Studies were identified by searching the databases PubMed, PsycInfo, and Cochrane Library in October 2019. We used the term ("Personnel Staffing and Scheduling"[Mesh] or "circadian disruption" or "circadian rhythm disruption" or "shift work" or "night shift" or "light at night") and ("Alcohol Drinking”[Mesh] or "alcohol"). First, studies whose titles clearly indicated they were not related to the subject were discarded. The remaining publications were obtained in full text and analyzed thoroughly. Additionally, their references were examined to locate any relevant publications that had not yet been identified through the search strategy. After this process, the studies that fit the previously defined inclusion criteria were included in the analysis (see Fig. 1). The studies' main statistical parameters such as odds ratios or $t$ tests were extracted where possible.

\section{Results}

The first search resulted in 668 articles. After exclusions by title and abstract, 195 articles were obtained and analyzed. The inclusion criteria were met by 14 of those studies [27, 28, 39-50].

All of these studies reported exclusively cross-sectional data. Samples included workers from the Scandinavian countries, such as Sweden [40], Finland [41], and Norway [39], as well as Australia [27, 28, 49], Japan [43, 44], Tunisia [45], Korea [46, 47], and China [42]. They spanned different working environments, such as nursing [39, 41], transportation [40], emergency medicine [48], and the steel industry [42]. Sample sizes range from $n=23$ [44] to $n=11,680$ [28]. In the study by Chatti et al.[45] including 330 subjects, the prevalence of alcohol consumption (25.8 vs. $16.0 \%)$ was significantly higher in shiftworkers ( $p=$ $0.04)$.

The study by Dorrian and Skinner[28] analyzed data from an Australian household survey, excluding participants in full-time study, the unemployed, and responders who did not drink alcohol. Shiftwork was defined as working outside the hours of 08:00-18:00 h Monday-Friday. Shiftworkers had significantly higher odds of drinking alcohol in short-term risky levels (odds ratio [OR] = $2.10 ; p<0.05$ ), defined here as 7 or more drinks for men and 5 or more drinks for women, compared with workers 


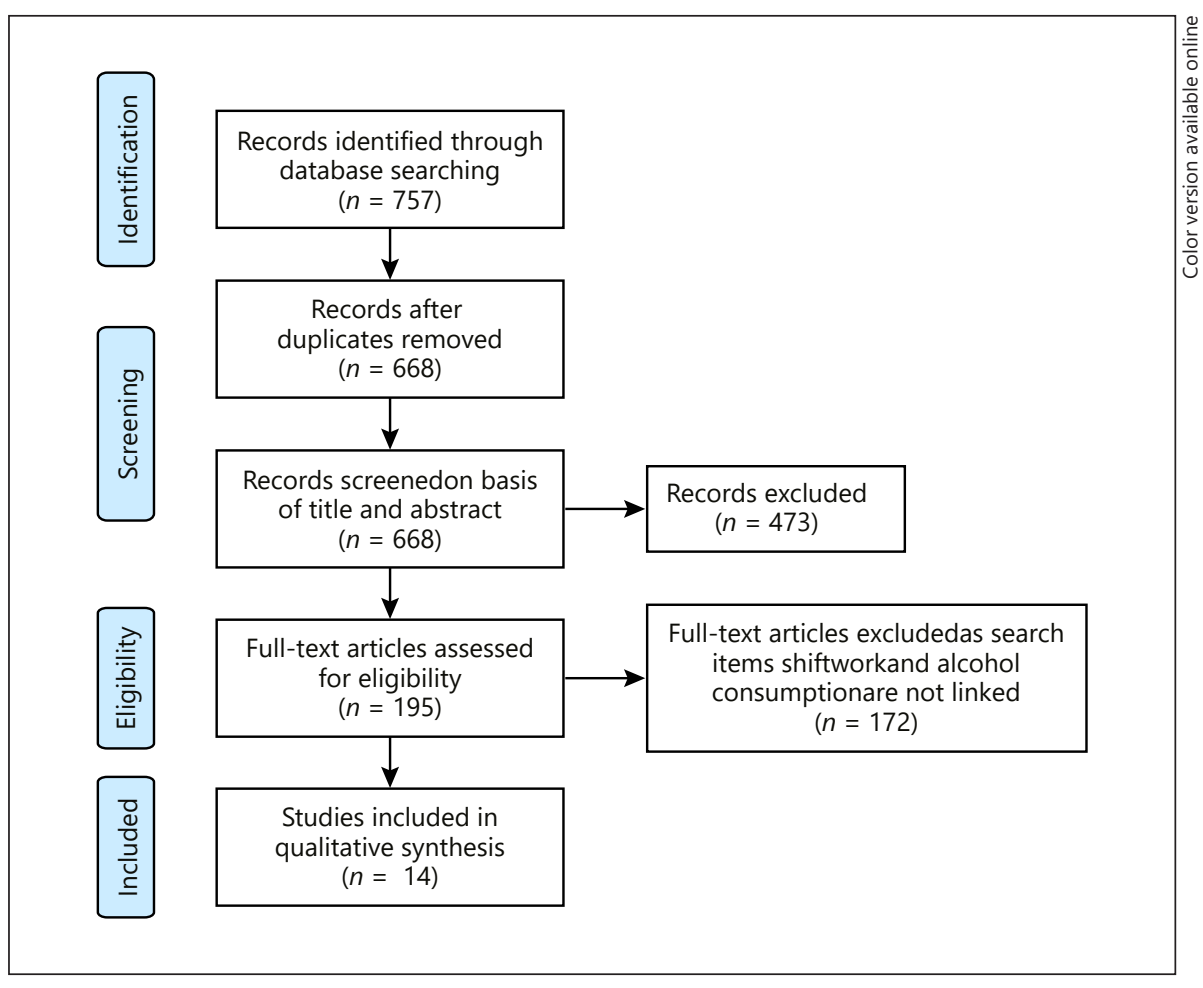

Fig. 1. Flowchart of search strategy.

not on a shift roster. However, being a shiftworker in this study also decreased the odds of consuming alcohol daily or near daily ( $\mathrm{OR}=0.20 ; p<0.05)$. According to the authors, this pattern might suggest binge-drinking behavior, defined in this study as "periods of heavy drinking followed by abstinence" [51], possibly reflecting the use of alcohol as a sleep aid during shift-associated sleeping problems.

Using logbooks, 23 full-time nurses in a metropolitan hospital completed daily recordings for 1 month (644 days, 377 shifts). The most commonly reported sleep aids were prescription medications (62.7\%), followed by alcohol (26.9\%). Total sleep duration was significantly shorter on workdays than days off $(p<0.01)$ [49]. Average alcohol consumption was $9.6 \pm 13.1$ standard drinks/week. One in 6 reported using alcohol as a sleep aid between shifts at least sometimes and nearly one-third reported consuming 12 or more drinks in $24 \mathrm{~h}$. However, those on 12 -h rotating shifts consumed more drinks per $24 \mathrm{~h}(p=$ $0.04)$ and had less sleep $(p<0.001)$ [27].

A study [42] on Chinese steel workers reported significantly higher rates of drinking alcohol at all among workers on a rotating shift schedule compared with daytime workers $(\mathrm{OR}=1.23 ; p=0.02)$. However, male gender and poor sleep were also significantly overrepresented in the shiftworking sample, but not controlled for. Neither patterns nor amounts of alcohol consumption are presented.

In a Japanese sample of male factory workers, Morikawa and colleagues $[43,50]$ found significantly higher rates of using alcohol as a sleep aid at least once per week in shiftworkers with night shifts than dayworkers $(\mathrm{OR}=$ $1.34 ; p=0.02)$. Levels of alcohol intake and rates of heavy drinking ( $>60 \mathrm{~g} /$ day) did not differ significantly between groups. However, additionally suffering from poor subjective sleep quality significantly increased the odds of heavy drinking among shiftworkers with night shifts, compared with dayworkers who reported good sleep $(\mathrm{OR}=2.14 ; p<0.05)$. Among dayworkers, poor sleep did not increase the odds of heavy drinking.

Ohida and colleagues [44] found significantly increased rates of self-reported use of alcohol as a sleep aid in Japanese nurses working in rotating shifts compared with dayworkers $(\mathrm{OR}=3.33 ; p<0.05)$. However, as most Japanese nurses work rotating shifts, the control sample of daytime nurses was relatively small in this study $(n=31)$.

Conflicting evidence is reported by Hermansson and colleagues [40], who used three different measures for alcohol consumption in a sample of employees working in the Swedish transportation sector: the self-report screening questionnaire Alcohol Use Disorders Identification Test (AUDIT) [52], the alcohol biomarker carbohydrate- 


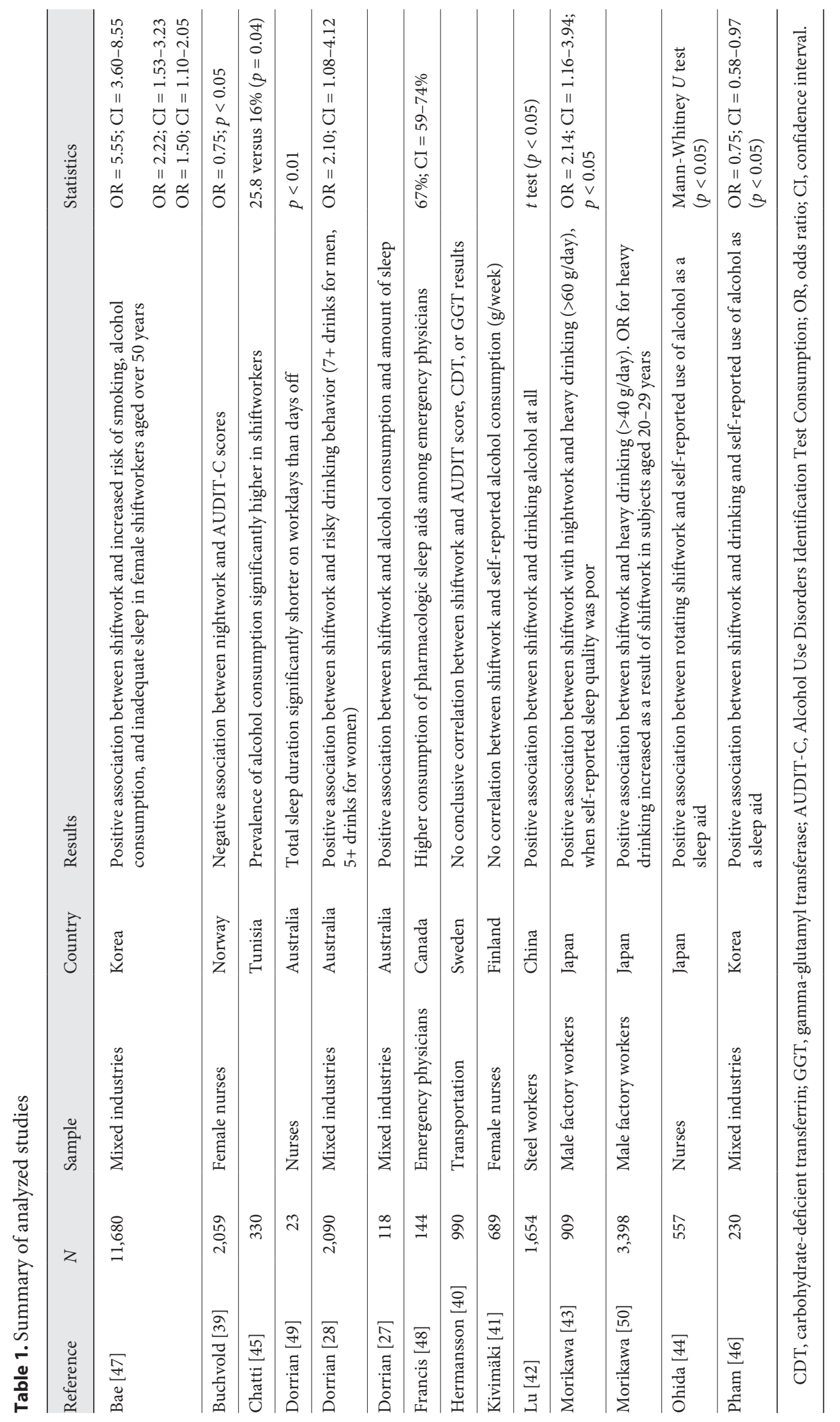


deficient transferrin, and the liver function test (serum gamma-glutamyl transferase). When using the carbohydrate-deficient transferrin method, working 2 shifts was associated with decreased risk for screening positive compared with daywork and three-shift work $(\mathrm{OR}=0.5 ; p=$ 0.03 ). The other 2 measures, however, yielded no statistically significant differences between the 3 groups.

In a sample of Norwegian nurses [39], having worked schedules including night shifts for more than 5 years was associated with lower scores on the Alcohol Use Disorders Identification Test Consumption (AUDIT-C), a selfreport screening instrument used to measure alcohol consumption ( $\mathrm{OR}=0.75 ; p<0.05)$. This is the only study in this review to report negative associations of night- or shiftwork with alcohol consumption.

Kivimäki and colleagues [41] report no statistically significant differences in self-reported weekly alcohol consumption or rates of heavy drinking (>210 g/week) between shiftworkers who had always been on shift schedules and dayworkers who had never done shiftwork in a sample of Finnish female nurses (Table 1). In the study by Pham and colleagues [51], shiftworkers showed a significantly higher percentage of those reporting a "desire to sleep well" as the reason for drinking ( $p=0.006)$. Psychosocial support from family and friends was correlated with a reduced risk of drinking ( $\mathrm{OR}=0.75$; 95\% confidence interval $[\mathrm{CI}]=0.58-0.97 ; p=0.030$ ).

Francis et al. [48] investigated the data of 198 eligible emergency physicians: 96 emergency physicians (67\%; $95 \% \mathrm{CI}=59-74 \%)$ had used a pharmacologic sleep aid at some time in their career. The most frequent sleep aids being used were non-benzodiazepine hypnotics (38\%), alcohol (17\%), and melatonin (15\%). A Korean study [47] with a total of 11,680 adults shows that female shiftworkers aged $\geq 50$ years demonstrated an increased risk of alcohol consumption $(\mathrm{OR}=2.22 ; 95 \% \mathrm{CI}=1.53-3.23)$ compared with female dayworkers.

\section{Discussion}

Sleep disorders, fatigue at work, reduced capacity for social life, and other psychosocial stress symptoms are common problems among shiftworkers $[1-4,15]$. In order to cope with these issues, shiftworkers might abuse alcohol in higher rates than dayworkers. Indeed, 4 of the reviewed studies find that heavy drinking or use of alcohol as a sleep aid is correlated to shiftwork in different professions as nurses, emergency physicians, and industrial workers. The definition for heavy drinking and short-term risky levels in these papers vary from up to 7 beverages in a row for a man and over 5 for a woman. One study reports correlations between heavy drinking and nightwork, whereas sleep problems occur more in the nightshift and alcohol serves as a self-sleep medication.

However, 3 more studies report conflicting or no evidence regarding elevated alcohol consumption in shiftworkers. This might be explained by the average alcohol consumption levels of Sweden, Norway, and Finland, where these studies were carried out. Compared with other countries, these countries have lower average alcohol use in the general population [53]. The link between shiftwork and alcohol use might be limited to countries where alcoholic beverages are more readily available and culturally accepted. Another reason for these conflicting findings might be the focus on average levels instead of patterns of alcohol use. Days or weeks of risky drinking might be followed by longer phases of restricted drinking in shiftworkers, caused by the alleviation of sleep problems during better tolerated shifts or by the disruption of social activities and routines, which might involve drinking, by their work schedule [54]. Two newer studies report higher odds ratio for the use of alcohol in correlation with shiftwork in emergency physicians and industrial workers. The participants used alcohol as a nap cap with the aim to fall asleep [55]. Apart from that, female shiftworkers older than 50 years showed higher risk of alcohol consumption compared with younger female workers.

To our knowledge, there are no longitudinal studies on this topic published to date. It should also be noted that all of the studies reported here rely either on self-report measures or on biomarkers, such as gamma-glutamyl transferase. The correlation of such measures with objective alcohol consumption is unclear, as researchers cannot ethically observe target populations' drinking patterns for a prolonged amount of time and thus have to rely on these potentially flawed measures. Still, the causal link chosen in this review pointing to binge drinking or heavy drinking as self-medication for sleep problems in shiftworkers seems plausible, whereas working in night shifts may be related to a higher risk for using alcohol to sleep better, not only in male shiftworkers but also in females over 50 years. Regarding the potential health risk of binge drinking and of sleep disorders for the wellbeing and health of the professions working in rotation shifts, sleep education should become a part of health promotion in all companies with people working in shifts. These results can be important for the implementation of programs for prevention and coping with sleep disorders and fatigue in connection with shiftwork in companies and hospitals. 


\section{Acknowledgement}

The literature research for the review has been initiated by Deutsche Gesellschaft für Arbeitsmedizin und Umweltmedizin e.V. (DGAUM) as a part of the Guidelines: Health Aspects of Shiftwork.

\section{Disclosure Statement}

The authors have no conflicts of interest to declare.

\section{Funding Sources}

There are no funding sources.

\section{References}

1 National Sleep Foundation. Facts about shift work disorder; 2018. [Cited 2018 Jul 1]. Available from: https://sleepfoundation.org/shiftwork/content/facts-about-shift-work-sleepdisorder.

2 Boisard P, Cartron D, Gollac M, Valeyre A. Temps et travail: la durée du travail. Dublin: European Foundation for the Improvement of Living and Working Conditions; 2002.

3 Destatis. Microzensus 2013. Bevölkerung und Erwerbstätigkeit: Beruf, Ausbildung und Arbeitsbedingungen der Erwerbstätigen in Deutschland. Wiesbaden: Statistisches Bundesamt; 2014

4 Destatis. Arbeiten, wenn andere schlafen; 2010. [Cited 2018 Jul 13]. Available from: https://www.destatis.de/DE/Publikationen/ STATmagazin/Arbeitsmarkt/2010_04/2010_ 04Nachtarbeit.html.

5 Vyas MV, Garg AX, Iansavichus AV, Costella J, Donner A, Laugsand LE, et al. Shift work and vascular events: systematic review and meta-analysis. BMJ. 2012;345,e4800.

6 Gan Y, Yang C, Tong X, Sun H, Cong Y, Yin $\mathrm{X}$, et al. Shift work and diabetes mellitus: a meta-analysis of observational studies. Occup Environ Med. 2015;72(1):72-8.

7 Wang F, Zhang L, Zhang Y, Zhang B, He Y, Xie S, et al. Meta-analysis on night shift work and risk of metabolic syndrome. Obes Rev. 2014;15(9):709-20.

8 Lin X, Chen W, Wei F, Ying M, Wei W, Xie $X$. Night-shift work increases morbidity of breast cancer and all-cause mortality: a metaanalysis of 16 prospective cohort studies. Sleep Med. 2015;16(11):1381-7.

9 Wang F, Yeung KL, Chan WC, Kwok CC, Leung SL, Wu C, et al. A meta-analysis on dose-response relationship between night shift work and the risk of breast cancer. Ann Oncol. 2013;24(11):2724-32.

10 Straif K, Baan R, Grosse Y, Secretan B, Ghissassi FE, Bouvard V, et al. Carcinogenicity of shift-work, painting, and fire-fighting. Lancet Oncol. 2007;8(12):1065-6.

11 Richter K, Acker J, Kamcev N, Bajraktarov S, Piehl A, Niklewski G. Recommendations for the prevention of breast cancer in shift workers. EPMA J. 2011;2(4):351-6.

12 Angerer P, Schmook R, Elfantel I, Li J. Night work and the risk of depression. Dtsch Arztebl Int. 2017;114(24):404-11.
13 Richter K, Acker J, Niklewski G. Personalised approach for sleep disturbances in shift workers. EPMA J. 2016;7:30-1.

14 Richter K, Acker J, Adam S, Niklewski G. Prevention of fatigue and insomnia in shift workers-a review of non-pharmacological measures. EPMA J. 2016;7:16.

15 Marschall J, Hildebrandt S, Sydow H, Nolting H-D. Gesundheitsreport 2017: analyse der Arbeitsunfähigkeitsdaten. Update: Schlafstörungen. In: Storm A, editor. Beiträge zur Gesundheitsökonomie und Versorgungsforschung. Hamburg: DAK-Gesundheit; 2017. p. 1-178.

16 Boivin DB, Boudreau P. Impacts of shift work on sleep and circadian rhythms. Pathol Biol. 2014;62(5):292-301.

17 Tucker P, Brown M, Dahlgren A, Davies G, Ebden P, Folkard S, et al. The impact of junior doctors' worktime arrangements on their fatigue and well-being. Scand J Work Environ Health. 2010;36(6):458-65.

18 Pilcher JJ, Lambert BJ, Huffcutt AI. Differential effects of permanent and rotating shifts on self-report sleep length: a meta-analytic review. Sleep. 2000;23(2):155-63.

19 Peter R, Alfredsson L, Knutsson A, Siegrist J, Westerholm P. Does a stressful psychosocial work environment mediate the effects of shift work on cardiovascular risk factors? Scand J Work Environ Health. 1999;25(4):376-81.

20 Nea FM, Kearney J, Livingstone MB, Pourshahidi LK, Corish CA. Dietary and lifestyle habits and the associated health risks in shift workers. Nutr Res Rev. 2015;28(2):143-66.

21 Ramin C, Devore EE, Wang W, Pierre-Paul J, Wegrzyn LR, Schernhammer ES. Night shift work at specific age ranges and chronic disease risk factors. Occup Environ Med. 2015; 72(2):100-7.

22 Coffey LC, Skipper JK, Jung FD. Nurses and shift work: effects on job performance and job-related stress. J Adv Nurs. 1988;13(2):24554.

23 Jamal M, Baba VV. Shiftwork and department-type related to job stress, work attitudes and behavioral intentions: a study of nurses. J Organiz Behav. 1992;13:449-64.

24 Conway PM, Campanini P, Sartori S, Dotti R, Costa G. Main and interactive effects of shiftwork, age and work stress on health in an Italian sample of healthcare workers. Appl Ergon. 2008;39(5):630-9.
25 Johnson EO, Roehrs T, Roth T, Breslau N. Epidemiology of alcohol and medication as aids to sleep in early adulthood. Sleep. 1998; 21(2):178-86.

26 Kaneita Y, Uchiyama M, Takemura S, Yokoyama E, Miyake T, Harano S, et al. Use of alcohol and hypnotic medication as aids to sleep among the Japanese general population. Sleep Med. 2007;8(7-8):723-32.

27 Dorrian J, Heath G, Sargent C, Banks S, Coates A. Alcohol use in shiftworkers. Accid Anal Prev. 2017;99(Pt B):395-400.

28 Dorrian J, Skinner N. Alcohol consumption patterns of shiftworkers compared with dayworkers. Chronobiol Int. 2012;29(5):610-8.

29 Landolt HP, Borbély AA. Alkohol und Schlafstörungen. Ther Umsch. 2000;57:241-5.

30 Walsh JK, Humm T, Muehlbach MJ, Sugerman JL, Schweitzer PK. Sedative effects of ethanol at night. J Stud Alcohol. 1991;52(6):597600.

31 Popovici I, French MT. Binge drinking and sleep problems among young adults. Drug $\mathrm{Al}-$ cohol Depend. 2013;132(1-2):207-15

32 Ragland DR, Greiner BA, Yen IH, Fisher JM. Occupational stress factors and alcohol-related behavior in urban transit operators. Alcohol Clin Exp Res. 2000;24(7):1011-9.

33 Smart RG. Drinking problems among employed, unemployed and shift workers. J Occup Med. 1979;21(11):731-6.

34 Mansukhani MP, Kolla BP, Surani S, Varon J, Ramar K. Sleep deprivation in resident physicians, work hour limitations, and related outcomes: a systematic review of the literature. Postgrad Med. 2012;124(4):241-9.

35 Richardson GS, Miner JD, Czeisler CA. Impaired driving performance in shiftworkers: the role of the circadian system in a multifactorial model. Alcohol Drugs Driving. 19891990;5-6(4-1):265-73.

36 Smith MJ, Colligan MJ, Tasto DL. Health and safety consequences of shift work in the food processing industry. Ergonomics. 1982;25(2): $133-44$.

37 Linseisen J, Wolfram G. Nährstoffzufuhr bei Dauernachtschicht-Arbeitern. Z Ernahrungswiss. 1994;33:299-309.

38 Moher D, Liberati A, Tetzlaff J, Altman DG. Preferred reporting items for systematic reviews and meta-analyses: the PRISMA statement. Open Med. 2009;3(3):e123-30. 
39 Buchvold HV, Pallesen S, Øyane NM, Bjorvatn $B$. Associations between night work and BMI, alcohol, smoking, caffeine and exercise: a cross-sectional study. BMC Public Health. 2015;15:1112.

40 Hermansson U, Knutsson A, Brandt L, Huss A, Rönnberg S, Helander A. Screening for high-risk and elevated alcohol consumption in day and shift workers by use of the AUDIT and CDT. Occup Med. 2003;53(8):518-26.

41 Kivimäki M, Kuisma P, Virtanen M, Elovainio M. Does shift work lead to poorer health habits? a comparison between women who had always done shift work with those who had never done shift work. Work Stress. 2001; 15:3-13.

42 Lu LF, Wang CP, Tsai IT, Hung WC, Yu TH, $\mathrm{Wu}$ CC, et al. Relationship between shift work and peripheral total and differential leukocyte counts in Chinese steel workers. J Occup Health. 2016;58(1):81-8.

43 Morikawa Y, Sakurai M, Nakamura K, Nagasawa SY, Ishizaki M, Kido T, et al. Correlation between shift-work-related sleep problems and heavy drinking in Japanese male factory workers. Alcohol Alcohol. 2013;48(2):202-6.

44 Ohida T, Kamal AMM, Sone T, Ishii T, Uchiyama $M$, Minowa $M$, et al. Night-shift work related problems in young female nurses in Japan. J Occup Health. 2001;43:150-6.
45 Chatti S, Debbabi F, Ben Abdelaziz A, Harbaoui R, Ghannem H, Mrizak N. Facteurs de risque cardiovasculaire chez les travailleurs postés d'une centrale de production d'électricité au centre tunisien. Ann Cardiol Angeiol. 2010;59:190-5.

46 Pham TT, Park B. Alcohol use disorder and health-related quality of life in Korean nightshift workers: a cross-sectional study using the KNHANES 2007-2015 data. PLoS One. 2019;14(4):e0214593.

47 Bae MJ, Song YM, Shin JY, Choi BY, Keum $\mathrm{JH}$, Lee EA. The association between shift work and health behavior: findings from the Korean National Health and Nutrition Examination Survey. Korean J Fam Med. 2017; 38(2):86-92.

48 Francis MN, Wishart IM, Williamson T, Iverach R. Use of pharmacologic sleep aids and stimulants among emergency medicine staff physicians in a Canadian tertiary care setting: a web-based survey. Ann Emerg Med. 2019; 73(4):325-9.

49 Dorrian J, Lamond N, van den Heuvel C, Pincombe J, Rogers AE, Dawson D. A pilot study of the safety implications of Australian nurses' sleep and work hours. Chronobiol Int. 2006;23(6):1149-63.
50 Morikawa Y, Nakamura K, Sakurai M, Nagasawa SY, Ishizaki M, Nakashima $M$, et al. The effect of age on the relationships between work-related factors and heavy drinking. J Occup Health. 2014;56(2):141-9.

51 Courtney KE, Polich J. Binge drinking in young adults: data, definitions, and determinants. Psychol Bull. 2009;135(1):142-56.

52 Saunders JB, Aasland OG, Babor TF, de la Fuente JR, Grant M. Development of the Alcohol Use Disorders Identification Test (AUDIT): WHO collaborative project on early detection of persons with harmful alcohol consumption: II. Addiction. 1993;88(6):791804.

53 Bloomfield K, Stockwell T, Gmel G, Rehn N. International comparisons of alcohol consumption. Alcohol Res Health. 2003; 27(1):95-109.

54 Webb GR, Redman S, Hennrikus D, Rostas JA, Sanson-Fisher RW. The prevalence and sociodemographic correlates of high-risk and problem drinking at an industrial worksite. $\mathrm{Br}$ J Addict. 1990;85(4):495-507.

55 Yamada C, Kobayashi K, Seki N. [Characteristics of male shift workers' drinking habits and factors related to drinking problems]. Nihon Koshu Eisei Zasshi. 2017;64(12):718-26. 